\title{
Study on Cultural Connotation of Zhong Fang's Seclusion
}

\section{in Zhong Nan Mountain}

\author{
Hang Jie \\ Xi'an Fan Yi University, Xi'an Shaanxi Province, 710105 \\ 46401238@qq.com
}

Key words: Zhong Fang; Seclusion; Zhong Nan, Cultural Connotation

\begin{abstract}
As one of the four recluses in Northern Song Dynasty, Zhong Fang went into politics after 30 years of seclusive life in Zhong Nan Mountain. At that time, he started to write books and participated in political affairs so that he was favored by Song Zhenzong. In his lifetime, Zhongfang had always been hovering at between politics and seclusion. Compared with other recluses in that period, his seclusion has distinguished features, which has something to do with both the Confucianism and more closely to do with the seclusion culture in Zhong Nan Mountain. Therefore, it is of great significance to study the cultural connotation of Zhong Fang's seclusion in Zhong Nan Mountain.
\end{abstract}

\section{Introduction}

In Spring and Autumn Period, with the collapse of its ritual, scholars just came into being. Recluses, as the unique part of scholars, lived in the mountains, far away from politics, exerted great influence on politics and culture in ancient times. So, in ancient times, there was a tradition of respecting recluses. In Northern Song Dynasty, the culture of seclusion had developed to its full despite of its weak politics. It was recorded in History of Song-Biography of Recluses that there were 43 recluses in total in Song Dynasty. Zhang Haiou added the total number up to 378 in his study. As a matter of fact, there were much more. Among those recluses, Zhong Fang, together with Chen Tuan, Wei Ye and Pan Lang, was called the Four Recluses in Northern Dynasty. It was only Zhong Fang who isolated himself in Zhong Nan Mountain.

The social and cultural background in Song Dynasty just provided convenience for the development of seclusion culture. "The material and spiritual civilization of Song Dynasty developed unprecedentedly in China's feudal history.” The advanced spiritual civilization of Song Dynasty had influence on many aspects of social life, and more importantly, it opened a wider space for the spiritual world of recluses. What's more, Song is a dynasty of culture-advocating and military-despising, so the upper class followed a tradition of recluses-respecting. It was recorded in History of Song-Biography of Recluses that 14 recluses had been recruited by the emperor. The recruitment of recluses indicated that their behavior patterns were accepted and recognized by mainstream of society, which had promoted the development of seclusion culture. Zhong Fang became a recluse under this social background.

Zhong Fang (955-1015), nicknamed by Ming Yi, whose father, an office secretary in civil chancery, named Xu, was transferred to Chang'an City. After his father died, Zhong Fang just left for Zhong Nan Mountain with his mother, lived by teaching and lecturing. During that period, he wrote Meng Shu with ten volumes, Si Yu Shuo, Biao Mei Zi composed of two parts and Tai Yi Ci Lu. 
He was unique and different from others in his childhood. It was recorded in History of Song-Biography of Zhong Fang that Zhong Fang was very quiet and indulged himself in reading. He could write at age of seven, and he never played with other children. Once his father wanted him to go into politics by receiving education, but finally he quitted school. Every time, when he came to Mountain Song and Mountain Hua, Fang felt awesome and loved it. At that time, while his friends went into politics, he chose to live in Zhong Nan Mountain and became a recluse. This different feeling of reclusiveness sprang from his childhood. In his entire life, Zhong Fang was hovering at between politics and seclusion, going through rough time, which just shaped his different reclusiveness.

\section{Hovering at Between Politics and Seclusion VS Confucianism}

It was recorded in History of Song-Biography of Zhong Fang that Zhong Fang was very talented but he didn't agree to participate in politics and serve the country for several times when Song Weigan recommended him to Song Zhen Zong. For the last time, recommended by Zhang Qixian, Zhong Fang was recruited as one of the key officials. Then he was 47 years old and participated in politics and serving the country. However, Zhong Fang had being hovering at between politics and seclusion for many times. Despite of this, Song Zhen Zong still hosted banquets for him to say farewell. Meanwhile, Song Zhen Zong asked other officials to accompany him and compose poems. In other words, an important reason why Zhong Fang could hover at freely between politics and seclusion is that Song Zhen Zong advocated culture while despised military.

All the emperors in Song Dynasty advocated culture while despised military, which has courtesy for recluses. Song Zhen Zong showed great respect for Zhong FANG. He was promoted again and again, and finally went to Mountain Tai with Song Zhen Zong to offer sacrifices to heaven and earth. This courtesy can be found in Shengshui Yan Tan Record and The Events of Song Dynasty. Song Zhen Zong once wrote like this, "Emperor Tang Ming treats Li Bai by preparing porridge by himself, while today I just accompany Fang to Mountain Tai to offer sacrifices to heaven and earth to show him my courtesy, and it's worthwhile.” Song Zhen Zong compared Zhong Fang as Li Bai while himself as Emperor Tang Ming, which represents the highest honor for Zhong Fang.

However, as a scholar, Zhong Fang seemed conflicted deep in his heart. He wanted to live a freewheeling life in the mountain, but still cared about the country and wanted to serve the country. Every time when he started to serve the country, he could not persist, while he would choose to go back to the mountain. When he lived in the tranquility of life, he worried about the country. It was just like what he wrote in the poem of Xiao Xiang Gan Shi, "Looking at the grass and flowers by the river, comes a sigh for the bygones. Talented Jia Yi eventually left for nothing, while QuYuan just drown himself in the river. The wild geese flies in desolate wild, while the swallow just settled in the Ting Temple. Countless heroes devoted themselves to the country, but eventually as died in the sea."

Standing by the river, Zhong Fang paid his respect to Qu Yuan to express his own feelings, because he can see his contradiction between going into politics and living in mountain for seclusion very clearly. The sharp comparison in this poem shows his own contradiction of being ambitious to serve the country and living in mountains for seclusion. The last sentence in this poem is not only a portrayal of Qu Yuan but also his own sigh. Another poem Ji Ai Hua Recluses goes like this, "I was so sick of fame and vanity, but served in the court. Felt very guilty about not contributing to the country, for deep in my heart, preferred the seclusion. Regretful in the court, while awake in the mountain and chase the freedom. The autumn wind has come, but when will the 
gloominess vanish? ".

In this poem, the poet expressed his feeling of "being in the court, but sick of fame and reputation" and finally expressed his sigh of " The old period is about to going somewhere." to show his inner voice of setting himself free.

Zhong Fang was very ambitious in his early age. Influenced by his father, he loved reading very much. That's why he went to politics and served the country with heart and soul. Even though he preferred to lived and isolated himself in the mountain, he had the dream and ambition of serving the country. However, educated with Confucianism, Zhong Fang was apprenticed to Chen Tuan and studied Taoism. Taoism warships immortality and it holds the thought that human can live in harmony with the charm of mountain. The contradiction of Zhong Fang's hovering at politics and seclusion might grow from the struggle of these two thoughts. Influenced by both Confucianism and Taoism, Zhong Fang was struggling in hovering at politics and seclusion.

Confucians hold that "Serving the country when there's no corruption, while quitting when the government is corruptive."(from The Analects-Taibo). The pre-condition of seclusion was that the government is corruptive with unjust administration, so scholars chose to live in mountains for seclusion. Zhong Fang was recruited for several times and was put into very important positions with nobility. That did not conform to seclusion worshipped by Confucianism. Therefore, his seclusion actually followed his inner heart, which conformed to Taoism that holds that "Human beings won't be destroyed by flood and drought. Because they think such sages as Yao and Xun could be cultivated anyway. So he's never takes governing the country as his cause in his life.”(Chuang-tzu, Free Travel). Taoists believe that sages never pursue fame and social status while pursuing spiritual freedom as the ultimate ideal of life, which is totally different from Confucianism.

\section{Mother's Parenting and Teachers' Influence}

Zhong Fang's love for living in the mountain is closely related to his mother. It was recorded in History of Song-Biography of Zhong Fang that when he was only no more than 10 years old, his father died. At that time, his brothers all went into politics, while Zhong Fang chose to live in a thatched cottage in Zhong Nan Mountain with his mother, which could shelter them from the rain and wind. Zhong Fang lived by tutoring. He discussed with his students and help them solve problems, so more and more students came to him for help. To show their gratitude, students just sent him some gifts and Zhong Fang and his mother just lived by helping others. When his father passed away, his brothers went to the court to serve the country. It was only Zhong Fang who lived with his mother in Zhong Nan Mountain for seclusion.

When his mother knew that Zhong Fang was called to the court, she reacted fiercely. She complained, "I told you not to teach students here. We just lived in the mountain for seclusion and never contacted with the outside world. Now that you chose to live for seclusion, why did you do that? Now, you see if we were found, I would choose to live in the mountain without you." Zhong Fang pretended that he was ill, so he didn't set off. His mother took the brush and ink slab and burnt them, then chose a very remote place in the deep mountains where there were very few people. Owing to his mother's disagreement, Zhong Fang finally decided not to serve the country and he chose to live a life of seclusion with his mother. Until the year when his mother passed away, Zhong Fang was called and finally recruited to the court. At that time, he was 47 years old.

\subsection{Teachers' Influence}

Zhong Fang's love for living in the mountain is also related to his teachers. Chen Tuan, as Taoist priest in Mountain Hua, held the idea that sleeping is very important for a long life. He often 
slept for several days, so he was called Shui Xian. According to a legend, Chen Tuan created Astrology and Pole Graph, so he was called by Song Tai Zong and named as "Sir Xi Yi" with a purple gown. Then apprenticed to Chen Tuan, Zhong Fang started to focus on the study of Taoism. It was recorded in History of Song Dynasty that Zhong Fang never got married in his lifetime and he was very sick of noise. Everytime when he went back to the mountain, he always isolated himself in a room and sat there alone silently, so he was always mocked. As for this, Chen Tuan wrote a poem for Zhong Fang, and it goes like this, "Feeling exhausted though it was not my own business, when can I have a rest? It must be done, otherwise I would be always pondering whether I should stay in the court to serve or live for seclusion." So he always remained silent and be himself in the face of others' mocking.

As the first apprentice to Chen Tuan, Zhong Fang was deeply influenced in his mind. Firstly, Chen Tuan was keen on sleeping for a long life. He restrained himself from eating so as to do practice. Zhong Fang never got married and he also followed his master. It was recorded in History of Song Dynasty that "Everyday all you need to do is just sitting in the cloud all the day." It indicated that Zhong Fang probably learned Taoism from his master. Secondly, Chen Tuan and Zhong Fang had the same experiences of being called by the emperor and bestowed with social status being the governmental officials. But he never was recruited, because he indulged himself only in cultivating himself to be the God in the mountains. While Zhong Fang was called for several times, he rejected and recruited again and again, which may followed the behavior patterns of his master Chen Tuan. Thirdly, it was recorded in Shao Shi Wen Jian Record that after Chen Tuan passed away, as the first apprentice, Zhong Fang set a gravestone for his master, so we can see he really had deep affection for Chen Tuan. He expressed his respect and admiration to Chen Tuan in the inscription. He valued his master Chen Tuan as Wang Bo in Tang Dynasty, which is a high compliment to him and also embodied his high social status at that time. It's not difficult for us to guess that Zhong Fang benefited a lot from Chen Tuan. Finally, according to Han Shang Yi Jie written by Zhu Zhen, as a teacher, Chen Tuan taught Zhong Fang Pole Graph and Astrology, which had profound influence on his philosophical thinking about nature and earth.

\section{Writing Books and Participating in Politics VS Congenital and Neo-Confucianism Origin}

Living in Zhong Nan Mountain, Zhong Fang had a special feeling and affection for the beauty of natural scenery of trees, water and the mountain. He was not only appreciating them on the surface, but also made a deep analysis. He wrote books about them. It was recorded in History of Song Dynasty that Zhong Fang wrote books like Meng Shu, Si Yu Shuo, Biao Meng Zi with two parts and Tai Yi Ci Lu. According to Tui Yin Zhuan, Zhong Fang wrote 12 chapters in Mei Shu with an aim of .............

He not only wrote books but also did teaching and cultivated some students. It was recorded in History of Song Dynasty that ChenYao Zuo, Yang Xie, Xue Tian, Gao Yan, Gao Yi and Han Tui were his students. According to Ying Shui Yan Tan Record, Liu Mengjie and Zhang He were among them, and Li Di was also one of his students according to Shao Shi Wen Jian Lu.

Moreover, Zhong Fang was favored and highly respected by Song Zhen Zong when he was in Tian Zi Courtyard, which had positive effect on Song Zhen Zong's governing of country. Once he advised Song Zhen Zong to implement the Confucian benevolence and persuaded him not to go out for travel. When Zhong Fang was looked down upon by other people, Song Zhen Zong objected and talked back with "Discussion Thirteen” proposed by Zhong Fang. It was recorded in History of Song Dynasty that "Discussion Thirteen" refers to various aspects of governing a country, including On Method, On Morality, On Punishment, On Weapons, On Civil and Military Officials, On System, 
On Teaching, On Reward and Punishment, On Crime, On Politics, On Lawsuit, On Tax and On Justice and Evil, which embodies Zhong Fang's political ambition of running a country. So it can be seen that Zhong Fang was very thoughtful about helping the Emperor govern the country.

Zhong Fang also taught his students about Xian Tian Tu and Pole Graph inherited from Chen Tuan. It was recorded in Han Shang Yi Jie written by Zhu Zhen that, “Chen Tuan handed Xian Tian Tu down to Zhong Fang, then to Mu Xiu, to Li Caizhi, then finally to Shang Yong. Zhong Fang then handed He Tu and Luo Shu down to Li Gai, then to Xu Jian, to Fan Echang, finally to Liu Mu, from generation to generation. Later, Shao Yong wrote a book named Priori. Zhou Dunyi, as the father of science, wrote a book named Tai Ji Tu Shuo, which means Zhong Fang made great contribution to the founding of Priori and Science.

Zhong Fang's seclusion is the outcome of the blinding of Confucianism and Taoism. It reflects both the official culture and seclusion culture. He set a good example of dealing well with the relationship between going into politics to become officials and seclusion for scholars in ancient China. More importantly, he is a typical example with wonderful experience which enriches the cultural connotation of seclusion in Zhong Nan Mountain.

\section{Acknowledgment}

Research Project: Education Department of Shaanxi Province, Study on Aesthetic Style and Value of Recluses from Northern Song Dynasty in Zhong Nan Mountain (10JK2060)

\section{References}

[1] Deng Guang Ming. On Several Questions of the History of Song Dynasty Research[J]. Social Science Front, 1986,2:56.

[2] Tuo Tuodeng. Volume 457 of the History of Song Dynasty[M]. Beijing: Zhong Hua Press, 1977.13422.

[3] Wang Pizhi. Shen Shui Yan Record: (Volume 4)[M]. Beijing: Zhong Hua Press, 1981,45.

[4] Song Cai Zheng Sun. Shi Lin Guang Ji: (Volume 9)[M]. Qing Wen Yuan Ge Si Ku Quan Shu. 